\title{
The Effects of Stabilization and Mckenzie Exercises on Transverse Abdominis and Multifidus Muscle Thickness, Pain, and Disability: A Randomized Controlled Trial in NonSpecific Chronic Low Back Pain
}

\author{
Mohammad Hosseinifar, PhD Candidate ${ }^{1)}$, Mohammad Akbari, PhD ${ }^{1}{ }^{*}$, \\ Hamid Behtash, MD ${ }^{2)}$, Mohsen Amiri, PhD ${ }^{3)}$, Javad Sarrafzadeh, PhD ${ }^{1)}$ \\ 1) Department of Physical Therapy, Tehran University of Medical Sciences: P.O. Box: 1545913187, \\ Tehran, Iran \\ 2) Department of Orthopedy, Tehran University of Medical Sciences, Iran \\ 3) Department of Physical Therapy, University of Welfare and Rehabilitation Sciences, Iran
}

\begin{abstract}
Purpose] This study compared the effectiveness of stabilization and McKenzie exercises on pain, disability, and thickness of the transverse abdominis and multifidus muscles in patients with nonspecific chronic low back pain. [Subjects] Thirty patients were randomly assigned into two groups: the McKenzie and stabilization exercise groups. [Methods] Before and after intervention, pain, disability, and thickness of the transverse abdominis and multifidus muscles were evaluated by visual analogue scale, functional rating index, and sonography, respectively. The training program was 18 scheduled sessions of individual training for both groups. [Results] After interventions, the pain score decreased in both groups. The disability score decreased only in the stabilization group. The thickness of the left multifidus was significantly increased during resting and contracting states in the stabilization group. The thickness of the right transverse abdominis during the abdominal draw-in maneuver, and thickness of the left transverse abdominis during the active straight leg raising maneuver were significantly increased in the stabilization group. The intensity of pain, disability score, thickness of the right transverse abdominis during the abdominal draw-in manouver, and thickness of the left transverse abdominis during active straight leg raising in the stabilization group were greater than those on the Mackenzie. [Conclusion] Stabilization exercises are more effective than McKenzie exercises in improving the intensity of pain and function score and in increasing the thickness of the transverse abdominis muscle.
\end{abstract}

Key words: Chronic low back pain, Stabilizaton exercises, Muscle thickness

(This article was submitted May 23, 2013, and was accepted Jun. 27, 2013)

\section{INTRODUCTION}

Lack of spinal core stability is supposed to be one of the important predisposing causes of recurrent low back pain $(\mathrm{LBP})^{1)}$. As a result, more attention has been paid to training of localized spinal stabilizer muscles in subjects with $\mathrm{LBP}^{2)}$. It is believed that specific stabilization exercises lead to changes in motor programing of the automatic feed-forward recruitment of deep core muscles ${ }^{3)}$. Therefore, stabilization exercises were suggested for chronic low back pain (CLBP) patients ${ }^{4-7)}$.

Recently, it has been reported that the use of stabilization exercises can improve the multifidus (MF) muscle size

*Corresponding author. Mohammad Akbari (E-mail: akbari_mo@tums.ac.ir)

(C2013 The Society of Physical Therapy Science

This is an open-access article distributed under the terms of the Creative Commons Attribution Non-Commercial No Derivatives (by-ncnd) License $<$ http://creativecommons.org/licenses/by-nc-nd/3.0/>. in acute $\mathrm{LBP}^{2)}$. However, few studies have reported the impacts of stabilization exercises on the size and function of stabilizer muscles ${ }^{8,9)}$. One study reported that the stabilization exercises led to an increase in the thickness of the stabilizer muscles ${ }^{8)}$. Another study showed borderline changes in contracting thickness of the TrA muscle following application of stabilization exercises ${ }^{9)}$. As a result, there is a lack of sufficient objective evidence about the effects of stabilization exercises on the thickness of the stabilizer muscles, especially thickness when contracted. Another approach is the McKenzie method ${ }^{10)}$. This approach is focused on sustained postures or repeated movements ${ }^{11)}$. Although McKenzie exercises could improve pain intensity in acute low back pain, subacute low back pain and $\mathrm{CLBP}^{12)}$, no study with regard to the effect of McKenzie exercises on the thickness of the stabilizer muscles in CLBP was found in a review of the literature.

As mentioned above, this study was carried out to determine and compare the effectiveness of stabilization and McKenzie exercises on pain, disability and TrA and MF 
muscle thickness in resting and contracting states in patients with nonspecific CLBP. It was hypothesized that stabilization exercises would increase the thickness of $\operatorname{Tr} A$ and MF muscles and that McKenzie exercises would not have any effects on the thickening of the TrA and MF muscles.

\section{SUBJECTS AND METHODS}

In this single randomized controlled trial study, the participants were selected through a simple non-probability sampling method and were randomly divided into two equal groups using sequences of random numbers. The first group $(\mathrm{n}=15)$ performed stabilization exercises, and the second group $(\mathrm{n}=15)$ performed McKenzie exercises. The examiner who assessed the outcomes was blinded to group assignment. The training program consisted of 18 sessions of supervised individual training for both groups, with the sessions performed 3 times per week for 6 weeks. Each training session lasted an hour and was performed at the Physiotherapy Clinic in the School of Rehabilitation, Tehran University of Medical Sciences, Tehran, Iran, between 2011 and 2012. Outcomes were measured in both groups before and after treatments. The study protocol was approved by the ethics committee of Tehran University of Medical Sciences. All patients provided written informed consent to participate in the study.

Thirty patients with nonspecific CLBP participated in this study on the basis of a clinical examination performed by a physician and the following inclusion criteria: age between 18-50 years, CLBP in the area between the costal margin and buttocks, with or without reference to the lower extremity (no radicular pain) that lasted more than 3 months. Patients were excluded if they had a history of recent fracture, trauma or previous surgery in the lumbar region; had spondylolysis or spondylolisthesis, spinal stenosis, neurological disorders, systemic diseases, cardiovascular diseases, diseases; were pregnant; were receiving concomitant treatment, with physical therapy modalities; or were receiving other therapies simultaneously ${ }^{7,13)}$.

After referral by a specialist, patients were reviewed based on the inclusion and exclusion criteria. Then demographic characteristics including age, sex, height, and weight were collected using a questionnaire. The pain history including the onset, location, and duration was recorded. Prior to and following the intervention, we measured pain, disability, and TrA and MF muscle thickness at rest and during contraction by visual analogue scale (VAS), Functional Rating Index (FRI) questionnaire, and ultrasound imaging, respectively.

The VAS was used for pain assessment ${ }^{13)}$. In this scale, pain was rated from 0 to $100 \mathrm{~mm}$, in which the 0 represented no pain and 100 represented maximum pain tolerance. Subjects were asked to mark the best number indicating their pain. The data were then recorded in the questionnaire ${ }^{12)}$.

Disability was evaluated through the Persian version of the FRI questionnaire. The questionnaire served as a tool specifically designed for quantifying mental comprehension of function and spinal pain in the clinical conditions. The reliability and validity of the questionnaire have already been demonstrated in previous studies ${ }^{14)}$. The questionnaire has 10 sections, and each section was rated using the same 5-point scale. Patients scored their existing disability by choosing one of the grades (the grades ranged from 0 to 4 , grade 0 meant without pain and able to complete the respective function, and grade 4 meant the maximum pain and inability to perform the functions). The overall score was calculated by the sum of the scores of all sections and was expressed by a percentage between 0 (no disability) and 100 (severe disability).

Ultrasound imaging is a reliable and reproducible method for evaluation of muscle structure, function, and activity ${ }^{15)}$. This method allows assessment of muscle activity by measuring changes in muscle geometry during contraction $^{16)}$. In this study, there was high intra-tester reliability for the ultrasound measurements of the MF and TrA muscle thicknesses at rest and during contraction (ICCs $=0.87$ to 0.96). To measure the thicknesses of the MF and TrA muscles, a B-mode ultrasound apparatus (MyLab 50 XVision, ESAOTE S.p.A, Genova Italy) was used. Measurement of the thicknesses of the TrA and MF muscles was performed in a resting position and during the tasks with submaximal muscle contraction on both sides ${ }^{17)}$. To record the thicknesses of the TrA and MF muscles, we used an LA523 linear probe (set to $12 \mathrm{MHz}$ ) and a CA431 convex array probe (set to $7.5 \mathrm{MHz}$ ). In order to measure TrA muscle thickness, the subjects were set in crook-lying position ${ }^{18)}$. The ultrasound probe was placed midway between the iliac crest and costal margin, on the midaxillary line, about $10 \mathrm{~cm}$ off the midline of body at the level of umbilicus ${ }^{19}$. TrA muscle thickness was measured in millimeters between the fascial lines, one centimeter away from the muscle junction in the direction of the thoracolumbar fascia ${ }^{18)}$. The two submaximal tasks were performed for the TrA muscle, the abdominal draw-in maneuver (ADIM) and active straight leg raising (ASLR ${ }^{20)}$. MF muscle thickness measurements were performed in the prone position with a pillow under the abdomen. The probe was placed along the spine, such that the midpoint of the probe was in line with the spinous process of the fourth lumbar vertebra. Then it was moved so that the facet joint between the fourth and fifth lumbar vertebrae was visible. This point is located directly on the MF muscle. The muscle thickness was measured from this point to the plane between the subcutaneous tissue and muscle ${ }^{16}$. The submaximal task for this muscle was elevation of the contralateral arm in a prone position with a small weight $(0.5 \mathrm{~kg})$ on the arm, the elbow at a right angle, and the glenohumeral joint at 120 degrees of abduction ${ }^{21)}$.

For warming up and before performing specific exercises, participants pedaled a stationary bike for 5 minutes and then did stretching exercises for 10 minutes $^{13)}$. Stabilization exercises were divided into 6 levels from easy to difficult. At the end of each training level, participants performed each exercise ten times for ten seconds with low intensi$\mathrm{ty}^{5}{ }^{5}{ }^{13)}$. During the treatment session, between 80 and 100 repetitions of the selected exercises were carried out in the McKenzie group ${ }^{22)}$.

The stabilization exercises were performed in 6 steps: 1) Segmental Control Exercises (SCE) with emphasis on train- 


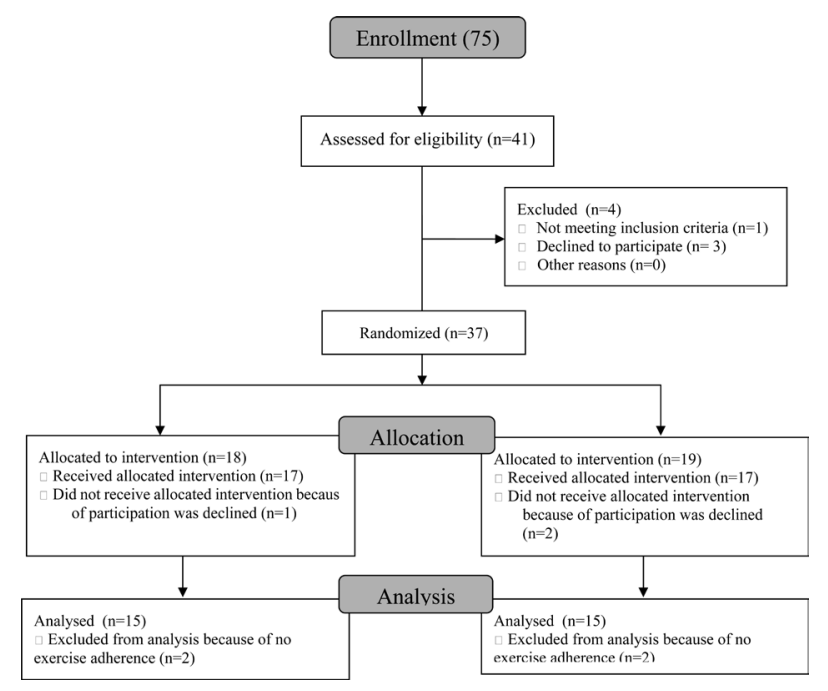

Fig. 1. Flow diagram outlining progress throughout the trial

ing the of isolated contraction of the TrA, MF, and pelvic floor muscles; 2) SCE with emphasis on co-contractions of the $\operatorname{TrA}, \mathrm{MF}$, and pelvic floor muscles in the prone, supine, and four-point kneeling positions; 3) closed kinematic chain SCE; 4) development of SCE into the low load apply by adding leverage of the limbs during open chain exercises; 5) development of SCE in functional situations; and 6) cocontraction of theTrA and MF muscles during application of an external load, complication of movements, increased load with the lumbar spine in the correct position, addition of a co-contraction pattern to light aerobic activities such as walking, and activities that have already exacerebated the symptoms ${ }^{4)}$.

In the Mckenzie group, 6 exercises were used: four extension-type exercises and two flexion-type and two flexion-type exercises. The extension-type exercises were performed in prone and standing positions, and the flexiontype exercises were performed in the supine and sitting positions. The final position of each exercise was maintained for 10 seconds $^{23)}$.

The data were collected over 10 months and were analyzed using SPSS version 17. They were tested for a

normal distribution using the Kolmogorov-Smirnov test. The independent samples t-test was used for comparing the Mckenzie and stabilization groups. The paired-t test was used to compare variables before and after training in each group. Statistical significance for all tests was accepted below the 0.05 level.

\section{RESULTS}

Demographic variables had a normal distribution. No significant difference was observed between the demographic characteristics of the two groups. The patients' demographic characteristics are listed in Table 1 . The study design and the corresponding flow diagram are shown in Fig. 1. The following data were not distributed normally after treatment: resting thickness of the left TrA, thickness of the left TrA during ADIM in the stabilization group, and
Table 1. Between-group baseline comparison of subjects' characteristics

\begin{tabular}{lcc}
\hline & Stabilization group & McKenzie group \\
\hline Age $(\mathrm{y})$ & $40.1 \pm 10.8^{\mathrm{b}}$ & $36.6 \pm 8.2$ \\
Height $(\mathrm{cm})$ & $170.5 \pm 8.5$ & $172.1 \pm 8$ \\
Weight $(\mathrm{kg})$ & $75 \pm 13$ & $78.4 \pm 10.6$ \\
$\mathrm{BMI}^{\mathrm{a}}$ & $25.8 \pm 4.1$ & $26.7 \pm 4.7$ \\
\hline
\end{tabular}

${ }^{\mathrm{a}} \mathrm{BMI}=$ body mass index,${ }^{\mathrm{b}}$ Values are means and standard deviations

resting thickness of the right $\operatorname{Tr} A$ in the McKenzie group.

Pain decreased in both the Mckenzie and stabilization groups after the intervention $(\mathrm{p}<0.05)$. The disability score decreased only in the stabilization group $(p<0.05)$. The mean thickness of the left MF muscle when contracted, resting thickness of the left TrA muscle, thickness of the right TrA muscle during ADIM, and thickness of the left TrA during ASLR increased in the stabilization group ( $\mathrm{p}$ $<0.05$ ) (Table 2).

Comparison of pain, function, and thickness of the TrA and MF muscles before treatment showed no difference between two groups $(\mathrm{p}>0.05)$. The changs in the pain and disability scores and right TrA muscle thickness during ADIM and the thickness of the left TrA muscle during ASLR were greater than those in the stabilization group $(p<0.05)$. Other variables showed no significant difference between the two groups ( $p>0.05)$ (Table 2).

\section{DISCUSSION}

The results of this study showed that pain decreased following application of stabilization and Mckenzie exercises. Disability decreased only after the application of stabilization exercises. The results indicated that the effect of stabilization exercises on pain and disability was greater than Mckenzie exercises in CLBP. Also, stabilization exercises were effective in increasing the resting thickness of the left TrA muscle, the thickness of the right TrA muscle during ADIM, the thickness of the left TrA muscle during active SLR, thickness of the left MF muscle when contracted. Comparison of the effects between the two methods of exercises on muscle thickness showed that stabilization exercises were more effective than Mckenzie exercises in increasing the thickness of the right TrA muscle during ADIM, and the thickness of left TrA muscle during ASLR.

Despite the borderline changes that occurred in the thickness of the TrA muscle when contracted in Vasseljen and Fladmark's study ${ }^{9}$, in the present study, the thicknesses of the TrA and MF muscles when contracted increased in some of the outcomes. In our study, the exercise types were different from those used in Vasseljen and Fladmark's study. The results of this study regarding the changes in resting thickness of the TrA muscles following application of stabilization exercises were consistent with the study by Akbari et $\mathrm{al}^{8)}$. They showed an increase in resting thickness of the TrA and MF muscles following the application of stabilization exercises ${ }^{8)}$. In the present study, the resting thickness of the left TrA increased. 
1544 J. Phys. Ther. Sci. Vol. 25, No. 12, 2013

Table 2. Means and standard deviations of variables within and between group comparison

\begin{tabular}{|c|c|c|c|c|}
\hline & \multicolumn{2}{|c|}{ Stabilization group } & \multicolumn{2}{|c|}{ McKenzie group } \\
\hline & Before & After & Before & After \\
\hline Pain (ordinal)* & $4.33 \pm 1.58^{b}$ & $1.53 \pm 1.40$ & $4.40 \pm 1.95$ & $2.66 \pm 1.39$ \\
\hline Function (ordinal)* & $39.13 \pm 15.53$ & $16.66 \pm 8.59$ & $46.16 \pm 17.87$ & $35.00 \pm 20.59$ \\
\hline Rt MF rest thick $(\mathrm{mm})^{\mathrm{a}}$ & $29.99 \pm 2.94$ & $31.48 \pm 4.76$ & $29.35 \pm 5.88$ & $31.05 \pm 5.74$ \\
\hline Lt MF rest thick (mm) & $30.76 \pm 4.58$ & $32.58 \pm 4.78$ & $29.72 \pm 5.50$ & $31.09 \pm 5.00$ \\
\hline Rt MF cont thick (mm) & $36.28 \pm 3.98$ & $37.79 \pm 4.74$ & $35.02 \pm 6.18$ & $36.32 \pm 5.15$ \\
\hline Lt MF cont thick (mm) & $37.06 \pm 3.87$ & $39.90 \pm 4.36$ & $36.64 \pm 5.31$ & $37.36 \pm 4.86$ \\
\hline Rt TrA rest thick (mm) & $3.45 \pm 0.63$ & $3.85 \pm 0.75$ & $3.30 \pm 0.67$ & $4.96 \pm 5.85$ \\
\hline Lt TrA rest thick (mm) & $3.54 \pm 0.92$ & $6.41 \pm 9.32$ & $3.35 \pm 0.75$ & $3.08 \pm 0.54$ \\
\hline Rt TrA thick ADIM (mm)* & $5.20 \pm 0.84$ & $6.06 \pm 1.12$ & $5.36 \pm 1.36$ & $5.06 \pm 1.27$ \\
\hline Lt TrA thick ADIM (mm) & $5.65 \pm 1.00$ & $11.33 \pm 20.95$ & $5.10 \pm 1.31$ & $5.20 \pm 1.24$ \\
\hline Rt TrA thick ASLR (mm) & $3.54 \pm 0.91$ & $4.03 \pm 0.99$ & $3.29 \pm 0.96$ & $3.50 \pm 0.89$ \\
\hline Lt TrA thick ASLR (mm)* & $3.81 \pm 0.99$ & $4.52 \pm 1.05$ & $3.45 \pm 0.86$ & $3.40 \pm 0.88$ \\
\hline \multicolumn{5}{|c|}{$\begin{array}{l}\text { a Rt MF rest thick = right multifidus resting thickness, Lt MF rest thick = left multifidus resting thickness, Rt } \\
\text { MF cont thick = right multifidus thickness when contracted, Lt MF cont thick = left multifidus thickness when } \\
\text { contracted, Rt TrA rest thick = right transverse abdominis resting thickness, Lt TrA rest thick = left transverse } \\
\text { abdominis resting thickness, Rt TrA thick ADIM = right abdominis thickness during abdominal draw-in ma- } \\
\text { neuver, Lt TrA thick ADIM = left transverse abdominis thickness during abdominal draw-in maneuver, Rt } \\
\text { TrA thick ASLR = right transverse abdominis thickness during straight leg rising, Lt TrA thick ASLR = left } \\
\text { transverse abdominis thickness during straightl rising. } \\
\text { b Values are means and standard deviations. } \\
{ }^{c} \text { Statistical difference at } p<0.05 \text {. } \\
\text { * p value for difference between groups. }\end{array}$} \\
\hline
\end{tabular}

Accordingly, depending on the purpose of exercise applications, effects of exercises on the muscles can lead to hypertrophy or neuromuscular adaptation ${ }^{9}$. With the emphasis placed on low-level contraction and isolation of the TrA muscles during stabilization exercises, it is expected that most of the effects of stabilization exercises are related to neuromuscular adaptation ${ }^{9}$. However, muscle hypertrophy typically occurs after 8 to 12 weeks of intensive strengthening exercises ${ }^{2,24)}$. Thus, we proposed that the short duration of the present study and effects of neuromuscular adaptation led to changes in some of the outcomes.

The findings of this study are consistent with the findings of previous studies in terms of improvement in pain and function following the application of stabilization exercises $^{4,6,8,13,25-29)}$. Also, stabilization exercises were found to be superior to McKenzie exercises in our study, as shown by the decreases in pain and disability, which is consistent with the results of other studies ${ }^{7,29)}$. Although stabilization exercises are the most important methods in rehabilitation of LBP disorders and in prophylaxis, the exact biological basis for the efficacy of stabilization exercises in LBP patients is not clear yet ${ }^{30)}$. Several mechanisms have been proposed to describe the effects of stabilization exercises on pain $^{26)}$. These mechanisms include reduction of load and improvement in the quality of movements following improvement in co-ordination of trunk muscles ${ }^{31)}$. In addition, the stabilization exercises targeted the main deep muscle affected by $\mathrm{LBP}^{29}{ }^{32}$. As a result, deep muscle stabilizer muscles could influence by stabilization exercises in LBP patients ${ }^{32}$. Therefore, a change in muscle thickness was only seen after stabilization exercises.

Considering the above mentioned points, pain reduction in the Mckenzie group might have occurred due to other causes without changes in the thickness of abdominal and MF muscles. This approach was focused on sustained postures or repeated movements, and pain reduction migth have been due to postural correction ${ }^{11)}$.

Therefore, both types of exercises reduced pain in patients with nonspecific CLBP. Disability was reduced only in stabilization group. Also, stabilization exercises were effective in increasing the resting thickness of theleft TrA muscle, thickness of the right TrA muscle during ADIM, thickness of the left TrA muscle during ASLR, and thickness of the left MF muscle when contracted. Stabilization exercises were more effective than Mckenzie exercises in reducing pain and disability, increasing the right TrA muscle thickness during ADIM, and increasing the left TrA muscle thickness during ASLR.

\section{ACKNOWLEDGEMENT}

The study was funded and supported by Tehran University of Medical Sciences (Grant No: P/26/d4/738).

\section{REFERENCES}

1) George SZ, Childs JD, Teyhen DS, et al.: Rationale, design and potocol for the prevention of low back pain in the military (POLM) trial. BMC Musculoskelet Disord, 2007, 8: 92. [Medline] [CrossRef]

2) Danneels LA, Cools AM, Vanderstraeten GG, et al.: The effects of three different training modalities on the cross-sectional area of the paravertebral muscles. Scand J Med Sci Sports, 2001, 11: 335-341. [Medline] [CrossRef]

3) Millisdotter M, Strömqvist B: Early neuromuscular customized training after surgery for lumbar disc herniation: a prospective controlled study. 
Eur Spine J, 2007, 16: 19-26. [Medline] [CrossRef]

4) O'Sullivan PB, Twomey LT, Allison GA: Evaluation of specific stabilization exercise in the treatment of chronic low back pain with radiologic diagnosis of spondylolysis or spondylolisthesis. Spine, 1997, 22: 2959-2967. [Medline] [CrossRef]

5) Sung PS: Multifidi muscles median frequency before and after spinal stabilization exercise. Arch Phys Med Rehabil, 2003, 84: 1313-1318. [Medline] [CrossRef]

6) Luomajoki H, Kool J, Bruin ED, et al.: Improvement in low back movement control, decreased pain and disability, resulting from specific exercise intervention. Sports Med Arthrosc Rehabil Ther Tecnol, 2010, 2: 11. [Medline] [CrossRef]

7) Goldby LJ, Moore AP, Doust J, et al.: A randomized controlled trial investigating the efficiency of musculoskeletal physiotherapy on chronic low back disorder. Spine, 2006, 31: 1083-1093. [Medline] [CrossRef]

8) Akbari A, Khorashadizadeh S, Abdi G: The effect of motor control exercise versus general exercise on lumbar local stabilizing muscles thickness: randomized controlled trial of patients with chronic low back pain. Back Musculoskelet Rehabil, 2008, 21: 105-112.

9) Vasseljen O, Fladmark AM: Abdominal muscle contraction thickness and function after specific and general exercises: a randomised controlled tria in chronic low back pain patients. Man Ther, 2010, 15: 482-489. [Medline] [CrossRef]

10) McCarthy CJ, Arnall FA, Strimpakos N, et al.: The biopsychosocial classification of non-specific low back pain: a systematic review. Phys Ther Rev, 2004, 9: 17-30. [CrossRef]

11) Petersen $T$, Larsen $K$, Jacobsen $S$ : One-year follow-up comparison of the effectiveness of McKenzie treatment and strengthening training for patients with chronic low back pain: outcome and prognostic factors. Spine 2007, 32: 2948-2956. [Medline] [CrossRef]

12) Skikić EM, Suad T: The effects of McKenzie exercise for patients with low back pain, our experience. Bosn J Basic Med Sci, 2003, 3: 70-75. [Medline]

13) Koumantakis GA, Watson PJ, Oldham JA: Trunk muscle stabilization training plus general exercise versus general exercise only: randomized controlled trial of patients with recurrent low back pain. Phys Ther, 2005, 85: 209-225. [Medline]

14) Ansari NN, Feise RJ, Naghdi S, et al.: The functional rating index: reliability and validity of the persian language version in patients with low back pain. Spine (Phila Pa 1976), 2011, 36: E1573-E1577.

15) Rasouli O, Arab AM, Amiri M, et al.: Ultrasound measurement of deep abdominal muscle activity in sitting positions with different stability levels in subjects with and without chronic low back pain. Man Ther, 2011, 16: 388-393. [Medline] [CrossRef]

16) Kiesel KB, Uhl T, Underwoodc FB, et al.: Rehabilitative ultrasound measurement of select trunk muscle activation during induced pain. Man Ther, 2008, 13: 132-138. [Medline] [CrossRef]

17) Teyhen DS, Miltenberger CE, Deiters HM, et al.: The use of ultrasound imaging of the abdominal drawing-in maneuver in subjects with low back pain. J Orthop Sports Phys Ther, 2005, 35: 346-355. [Medline] [CrossRef] 18) Saliba SA, Croy T, Guthrie R, et al.: Differences in transverse abdominis activation with stable and unstable bridging exercise in individuals with low back pain. N Am J Sports Phys Ther, 2010, 5: 63. [Medline]

19) Costa LO, Maher CG, Latimer J, et al.: An investigation of the reproducibility of ultrasound measures of abdominal muscle activation in patients with chronic non-specific low back pain. Eur Spine J, 2009, 18: 1059-1065. [Medline] [CrossRef]

20) Kiesel KB, Uhl TL, Underwood FB, et al.: Measurement of lumbar multifidus muscle contraction with rehabilitative ultrasound imaging. Man Ther, 2007, 12: 161-166. [Medline] [CrossRef]

21) Hebert JJ, Koppenhaver SL, Magel JS, et al.: The relationship of transversus abdominis and lumbar multifidus activation and prognostic factors for clinical success with a stabilization exercise program: a cross-sectional study. Arch Phys Med Rehabil, 2010, 91: 78-85. [Medline] [CrossRef]

22) Twomey LT, Taylor JR: Physical Therapy of the Low Back. New York: Churchill Livingstone, 1994, pp 171-196.

23) Kinkade S: Evaluation and treatment of acute low back pain. Am Fam Physician, 2007, 75: 1181-1188. [Medline]

24) Enoka RM: Neural adaptations with chronic physical activity. J Biomech, 1997, 30: 447-455. [Medline] [CrossRef]

25) Cairns MC, Foster NE, Wright C: Randomized controlled trial of specific spinal stabilization exercise and conventional physiotherapy for recurrent low back pain. Spine, 2006, 31: E670-E681. [Medline] [CrossRef]

26) Costa LO, Maher CG, Latimer J, et al.: Motor control exercise for chronic low back pain: a randomized placebo-controled trial. Phys Ther, 2009, 89: 1275-1286. [Medline] [CrossRef]

27) Muthukrishnan R, Shenoy S, Jaspal SS, et al.: The differential effects of core stabilization exercise regime and conventional physiotherapy regime on postural control parameters during perturbation in patients with movement and control impairment chronic low back pain. Sport Med Arthrosc Rehabil Ther Technol, 2010, 2: 13. [Medline] [CrossRef]

28) Ferreira ML, Ferreira PH, Latimer J, et al.: Comparison of general exercise, motor control exercise and spinal manipulative therapy for chronic low back pain: a randomized trial. Pain, 2007, 131: 31-37. [Medline] [CrossRef]

29) França FR, Burke TN, Hanada ES, et al.: Segmental stabilization and muscular strengthening in chronic low back pain - a comparative study. Clinics, 2010, 65: 1013-1017. [Medline] [CrossRef]

30) Hodges P: Transversus abdominis: a different view of the elephant. Br J Sports Med, 2008, 42: 941-944. [Medline] [CrossRef]

31) Hodges PW, Moseley GL: Pain and motor control of the lumbopelvic region: effect and possible mechanisms. J Electromyogr Kinesiol, 2003, 13: 361-370. [Medline] [CrossRef]

32) Hodges P: Lumbo-Pelvic Stability: A Functional Model of the Biomechanics and Motor Control. In: Therapeutic Exercise for lumbopelvic Stabilization; A Motor Control Approach for the Treatment and Prevention of Low Back Pain. Edinburgh: Churchill Livingstone, 2004, pp 13-14. 